\title{
Editorial - The Bibliometric Measurements of the Polish Journal of Neurology and Neurosurgery (Neurologia i Neurochirurgia Polska) for 2017
}

We are pleased to announce that the CiteScore ${ }^{\mathrm{TM}}$ (CS) of the Polish Journal of Neurology and Neurosurgery (Neurologia i Neurochirurgia Polska) for 2017 increased, now registering at

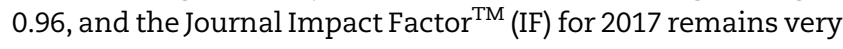
stable at 0.81 .

CS is a metric of citation impact of regularly published titles based upon analysis of Elsevier's Scopus database. There are 25,322 peer reviewed scientific titles (journals, books, conference proceedings) covered by Scopus. For comparison, Journal Citation Reports (source for calculating the IF) covers only a little over 11,000 titles.

CS is a result of division of an average number of citations received by a title in a calendar year by the number of all papers published in a journal in the previous three years.

CS values are available from 2011. The CS of the Polish Journal of Neurology and Neurosurgery (Neurologia i Neurochirurgia Polska) has increased throughout those years from 0.53 in 2011 to 0.96 in 2017 (Fig. 1, bars in blue), with a significant increase in comparison to 2016.

IF has been calculated annually since 1975. Currently, the IF is published by Clarivate Analytics. The IF of a journal

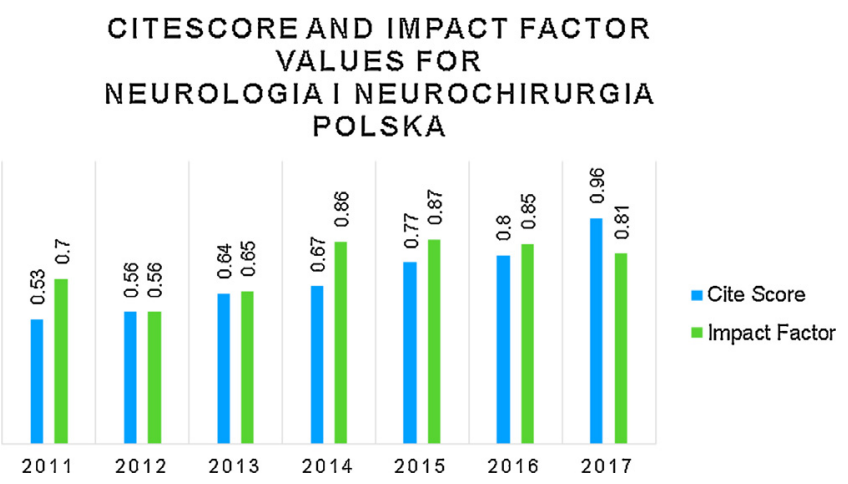

Fig. 1 - Values of CiteScore ${ }^{\mathrm{TM}}$ and Impact Factor ${ }^{\mathrm{TM}}$ for the Polish Journal of Neurology and Neurosurgery (Neurologia i Neurochirurgia Polska) from 2011 to 2017. represents the number of citations received in the year for articles published in the journal during the two preceding years divided by the total number of articles published in the journal during the two preceding years. Thus the measurement of IF is similar to CS, but over the period of two years only and with a smaller number of referenced journals.

IF of Polish Journal of Neurology and Neurosurgery (Neurologia i Neurochirurgia Polska) remains very stable (Fig. 1, bars in green).

We thank all authors who submitted their work to the Journal. We thank previous Editor-in-Chief, Professor Andrzej Szczudlik, his Associate Editors, and Editorial Board members for their leadership and work to accomplish this spectacular success. Finally, we thank Elsevier's editorial staff, particularly Mr. Jaap Albertsma and Ms. Justyna Kasprzycka, for their assistance in every day operations of our Journal.

We are very satisfied with this result, but we also believe that the potential of the Polish Journal of Neurology and Neurosurgery (Neurologia i Neurochirurgia Polska) is much higher. Therefore, we will work hard to achieve even better results. We encourage our authors to submit their best work to our Journal. We hope that our readership of neurologists, neurosurgeons, clinicians engaged in research, and basic scientists will expand further. We welcome comments and suggestions from our readers on how to make our Journal an even better scientific forum.

Mariusz Siemiński M.D., Ph.D.(Technical Editor) Jarosław Sławek M.D., Ph.D.(Co-Editor-in-Chief) Zbigniew Wszołek M.D.(Co-Editor-in-Chief)

https://doi.org/10.1016/S0028-3843(18)30304-9 0028-3843/ 